\title{
CONTRIBUIÇÕES DO CANTO CORAL NA ESCOLA PARA A FORMAÇÃO INTEGRAL: O QUE DIZEM OS ESTUDANTES
}

\author{
Leonardo Pavanello Júnior \\ Marcia Regina Selpa Heinzle $e^{(*)}$
}

\section{PRIMEIRAS PALAVRAS}

"pensaremos que a formação humana dos educandos ou passa pela totalidade do convívio, das trocas, dos saberes, dos rituais, das relações sociais da escola ou não acontecerá [...]". (ARROYO, 2000, p.116)

Ancorando-se nas palavras de Arroyo, "pensaremos que a formação humana dos educandos ou passa pela totalidade do convívio, das trocas, dos saberes, dos rituais, das relações sociais da escola ou não acontecerá [...]".(ARROYO, 2000, p. 116). compreende-se que o processo de formação de estudantes na escola vai além das práticas escolarizadas, ela inclui o convívio e interação social com outros sujeitos, discursos, práticas e, especialmente, com a relação para além dos muros escolares. A formação está articulada à sociedade na qual vive o estudante, pois existe um intercâmbio de ações da escola para a sociedade e vice-versa. Assim, a formação do educando transcende uma lista de conteúdos: abrange dimensões humanas do sujeito.

É tendo essa concepção como pano de fundo que este trabalho discute o atual 'espaçotempo' de formação, sob o olhar de estudantes participantes de práticas de canto coral na escola, acerca do seu processo de formação e de como as práticas do coral refletiram nessa formação. Este artigo é, então, orientado pelo objetivo de analisar as possíveis contribuições do canto coral para a formação integral de estudantes. Os dados sinalizam as duas principais dimensões de análise ora apresentadas: as contribuições que dizem respeito à formação escolar, incluindo as aprendizagens em determinadas disciplinas cursadas; e as contribuições que vão além da escola, que incluem a

\footnotetext{
${ }^{(*)}$ Leonardo Pavanello Júnior. Professor, vereador e músico. Mestre em Educação pelo Programa de Pós-graduação em Educação (Mestrado em Educação) da Universidade Regional de Blumenau (FURB). Graduado em Licenciatura em Música (FURB). Professor efetivo na Rede Municipal de Ensino de Presidente Getúlio e membro do Grupo de estudos e pesquisas do Ensino Superior: propostas curriculares, processos metodológicos e avaliativos (GEPES).

Marcia Regina S. Heinzle. Doutorado em Educação (UNICAMP, 2012). Mestrado em Educação (FURB, 2002). É coordenadora adjunta e professora do Programa de Pós-graduação em Educação FURB (2017). Participante do Grupo Internacional de Estudos e Pesquisas em Educação Superior GIEPES/UNICAMP. Rede Iberoamericana de pesquisas em políticas e processos de Educação Superior Ênfase nos seguintes temas: Educação Superior, Docência Universitária, Políticas Curriculares, Internacionalização do Currículo.
} 
atuação social dos estudantes com seus pares (como a família) e a representação que o aluno tem de si mesmo, a sua formação identitária.

A fim de responder ao objetivo ora proposto, após essa breve introdução, são apresentados o contexto e os acordos metodológicos de geração dos dados. Em seguida, são discutidas as duas dimensões de análise dos dados. E, por fim, apresentadas as compreensões acerca do panorama formado pelas análises discutidas neste trabalho.

\section{CENÁRIO E ACORDOS METODOLÓGICOS}

O cenário no qual a pesquisa foi realizada é uma escola de uma Rede Municipal de Ensino de Santa Catarina. A instituição atende estudantes do ensino fundamental e possui um espaço que oferece várias atividades extracurriculares, que estão contempladas no Projeto Político Pedagógico (PPP) da escola, como: coral, aulas de violão e bateria, danças, capoeira e teatro.

A escola dispõe de uma sala cultural, que oferece aos alunos diferentes linguagens artísticas, a saber: danças, canto coral, teatro, capoeira e aulas de violão e bateria. A escola já possuía há muito tempo aulas de dança e de coral que, por um período, aconteceram das $12 \mathrm{~h}$ às $13 \mathrm{~h}$, e das $17 \mathrm{~h}$ às $18 \mathrm{~h}$, para contemplar os estudantes dos dois turnos. Essas atividades eram regidas por professores da escola que tinham formação em outra área, mas que possuíam uma afinidade com as linguagens da arte.

Com o passar do tempo, as linguagens artísticas ganharam mais espaço no currículo escolar, e por sua vez a formação dos profissionais dessa área são ressignificados. Atualmente os professores possuem uma formação específica para trabalhar com as distintas linguagens a saber: visuais, música, cênicas e dança.

Outra conquista importante na escola foi a inserção no Programa Mais Educação, no ano de 2015. O Programa Mais Educação instituído pela Portaria Interministerial n. ${ }^{\circ}$ 17/2007 e pelo Decreto 7.083, de 27 de janeiro de 2010, integra as ações do plano de desenvolvimento da educação (PDE), como uma estratégia do governo federal para introduzir a ampliação da jornada escolar e a organização curricular, na perspectiva da educação integral (BRASIL, 2014).

Os sujeitos participantes da pesquisa são estudantes que integraram o coro de uma escola de uma Rede Municipal de ensino. Participaram da pesquisa 15 estudantes do coral no ano de 2014. Como critério de inclusão, optou-se pelos estudantes que já faziam parte do coro nos anos anteriores. Os demais estudantes, que entraram após esse período, não participaram desta pesquisa, 
em decorrência da data de geração de dados. Ressalta-se, ainda, que dos 15 estudantes, nove também participavam de aulas de violão oferecidas na escola.

Entende-se que, quando os participantes da pesquisa são as crianças, o compromisso com a ética é ainda maior. A capacidade da criança em compreender e opinar precisa ser avaliada e eticamente respeitada. Coube, assim, ao pesquisador encontrar alternativas para atingir seus objetivos na pesquisa sem ferir os princípios da ética (EL GUINDY, 2004). Com isso, se faz necessário que o anonimato $^{1}$ dos participantes seja garantido de forma a evitar que ele sofra qualquer consequência advinda dos resultados da investigação (RAITZ; FERREIRA; GUERRA, 2006). Por isso, optou-se por representar os participantes da pesquisa por meio de nomes de artistas e compositores musicais. Essas denominações foram escolhidas pelos próprios sujeitos, a partir de canções de diferentes artistas apresentadas pelo professor e pesquisador em um dos ensaios do coral.

Os dados analisados neste trabalho foram gerados por meio de memoriais descritivos, utilizado para compreendermos as trajetórias dos estudantes no decorrer das aulas de música. $O$ que mudou na sua vida com a prática de canto coral? Quais as motivações em participar das aulas e quais as contribuições da prática de canto coral na sua vida e na formação escolar? Analisaram-se os relatos de suas experiências em relação às aulas de música. Vale salientar, ainda, que o memorial descritivo foi apresentado aos participantes da pesquisa como uma atividade à parte daquelas empreendidas no âmbito das aulas de canto coral. A atividade de produção dos memoriais descritivos foi orientada por um roteiro entregue aos estudantes e respondido por eles no espaço escolar em um dos ensaios do coro. Ressalta-se que o memorial pode ser considerado como instrumento de avaliação e de investigação, pois "o memorial é um documento pessoal do tipo diário" (ANDRE, 2004, p. 283). Adaptou-se o memorial para os alunos preencherem, assim obtivemos os registros dos pesquisados.

\section{CONTRIBUIÇÕES DO CANTO CORAL À FORMAÇÃO INTEGRAL DOS ESTUDANTES}

Neste momento, focalizam-se as contribuições dessa prática na formação integral e no contexto escolar, a partir dos dizeres dos estudantes participantes da pesquisa.

Compreende-se que a educação integral visa a um processo de formação do ser humano de forma mais ampla, ou seja, a formação integral do sujeito. Essa formação se constitui a partir de

\footnotetext{
${ }^{1}$ Pesquisa aprovada pelo comitê de ética sob o número: 38822414.0.0000.5370.
} 
outros olhares fundamentais, como das artes em suas diferentes linguagens: visuais, música, cênicas, dança, para assim desenvolver o lado artístico e outras dimensões do sujeito. Diferente do termo educação de tempo integral, que está relacionado ao aumento da jornada escolar dos estudantes.

Ao pensar em formação integral e educação integral, apoia-se em Arroyo (2000), que afirma que a formação integral é uma concepção de que o ser humano é um sujeito total (integral) enquanto sujeito de conhecimento, de cultura, valores, ética, identidade, memória e imaginação.

O ser humano é compreendido, sob essa ótica, como um sujeito plural. Essa pluralidade precisa, então, ser contemplada pelos processos educacionais. Para Guará (2006, p. 16),

Na perspectiva de compreensão do homem como ser multidimensional, a educação deve responder a uma multiplicidade de exigências do próprio indivíduo e do contexto em que vive. Assim, a educação integral deve ter objetivos que construam relações na direção do aperfeiçoamento humano. [...] A educação, como constituinte do processo de humanização, que se expressa por meio de mediações, assume papel central na organização da convivência do humano em suas relações e interações, matéria prima da constituição da vida pessoal e social.

Das palavras da autora, emerge o sentido da formação humana como objetivo da educação integral. Sob essa perspectiva, a formação contempla as distintas dimensões do sujeito, a fim de formá-lo para atuar em interações sociais diversas. A educação é compreendida como processo de humanização, de inserção ativa dos estudantes na sociedade.

Compreende-se que a formação integral possui uma forte conexão com as funções da música, que costumam estar relacionadas à experiência humana. Ou seja, na forma de se expressar, pensar, agir e sentir. Identifica-se, de um lado, os valores intrínsecos da música, ligados à música como área de conhecimento. De outro lado, os valores extrínsecos, aqueles que indicam a música auxiliando como dispositivo para relaxar, memorizar, aprender um idioma, autoconfiança, concentração, trabalho em equipe, respeito, cooperação. É nesses valores extrínsecos, ou seja, nos valores extramusicais que foca este trabalho.

Ao considerar os estudos e pesquisas que revelam a importância da música na formação do ser humano e a obrigatoriedade da Lei 11.769/2008, que determina a música como um dos componentes curriculares, percebe-se, ainda, a ausência de práticas musicais nas escolas. Observase, também, outra problemática: há uma compreensão que a disciplina de música irá formar 
músicos, ou seja, proporcionará uma formação tecnicamente instrumentista. Ao contrário desse propósito, segundo Hentschke e Del Ben (2003, p. 179), o papel da música na escola é

[...] auxiliar crianças, adolescentes e jovens no processo de apropriação, transmissão e criação de práticas músico-culturais como parte da construção de sua cidadania. $\mathrm{O}$ objetivo primeiro da educação musical é facilitar o acesso à multiplicidade de manifestações musicais da nossa cultura, bem como possibilitar a compreensão de manifestações musicais de culturas mais distantes. Além disso, o trabalho com música envolve a construção de identidades culturais de nossas crianças, adolescentes e jovens e o desenvolvimento de habilidades interpessoais.

Segundo Granja (2010, p. 106), "a linguagem musical tem um potencial transformador enorme, pois é um conhecimento que valoriza o que há de mais humano nas pessoas: a emoção, o transcendental e a paixão". O autor defende, ainda, a ideia de que a música é um conhecimento necessário para as pessoas e sociedade.

De acordo com as ideias abordadas, pode-se afirmar que a educação musical tem um importante papel no processo de formação dos educandos. Ressalta-se, também, que quanto mais cedo os estudantes forem inseridos em um ambiente musical, mais tempo elas terão para desenvolver suas habilidades e ter a consciência de melhor exercerem seu papel social dentro da atual sociedade.

Concebe-se a música, e demais atividades artísticas, como atividades que desenvolvem a mente humana, proporcionando o bem-estar, colaborando para o equilíbrio, desenvolvendo assim o raciocínio, a concentração e outras habilidades importantes para o ser humano. Conforme Sekeff (2007, p. 130), pautar a música na educação é apontar a sua necessidade nas escolas, “[...] auxiliar o educando a concretizar sentimentos em formas expressivas, favorecer a interpretação de sua posição no mundo, possibilitar a compreensão de suas vivencias, conferir sentido e significado à sua condição de indivíduo e cidadão".

A música vem sendo valorizada em muitos países como um componente essencial na formação das pessoas, ela não necessariamente precisa ser aprendida de maneira formal. A educação musical pode se dar em um processo informal, que proporcione requisitos significativos para a vida das pessoas. Conforme Salienta Joly (2003, p. 113),

A inserção das artes, incluindo a música, no processo de formação do indivíduo, está sendo muito valorizada por algumas sociedades atualmente. Na grande maioria dos países desenvolvidos, [...], há um reconhecimento de que a educação musical, seja ela formal ou informal, ensina às crianças requisitos importantes para a vida adulta. 
Depara-se, então, com a música contribuindo para aprendizagens escolares e para a formação do indivíduo. Se a educação musical ensina requisitos importantes para a vida adulta, compreende-se que é válido ela estar presente nas escolas. Por essa razão, entende-se que devem expandir reflexões acerca da relevância da música no cotidiano das crianças. Depreende-se, também, ser necessário que essa discussão ultrapasse os muros da escola e as salas de aula.

Compreende-se que a música no cotidiano escolar pode favorecer a aprendizagem, pois atende a vários aspectos do desenvolvimento humano (mental, social, físico, emocional). Segundo Sekeff (2007, p. 17), "a música é um poderoso agente de estimulação motora, sensorial emocional e intelectual, informa a psicologia”. Desse modo, pode ser vista por diferentes concepções, como um meio para facilitar o processo educacional, em virtude de colaborar para diferentes áreas do desenvolvimento.

Por meio dos dizeres dos estudantes, sujeitos que vivenciam a prática do canto no cotidiano escolar, portanto, discute-se a respeito das contribuições da música no contexto educacional. Sistematizam-se as discussões, levando em consideração as similaridades que emergiram dos memoriais escritos pelos estudantes. São apresentadas, então, dimensões de análise que abrangem diferentes contribuições do canto coral no cotidiano dos estudantes e que dizem respeito a aspectos como o desempenho escolar, a responsabilidade e o desenvolvimento intelectual. Passa-se, então, às discussões:

Cássia Eller (9 anos) - Nós aprendemos a ler com ele (coral), é legal cantar pra quem gosta [...] Eu aprendo mais no coral, lá a gente tem mais vontade de estudar [...]

Marcelo D2 (10 anos) - melhorou os meus estudos na escola e eu sei que eu posso melhorar ainda mais.

Mallu Magalhães (9 anos) - Em inglês melhorei português, história e outras matérias e simplesmente amo vir para o coral.

Roberta Sá (13 anos) - na roda de conversa - É, na língua estrangeira, porque aqui a gente canta música em inglês e aqui a gente está aprendendo a pronuncia da música. E lá a gente aprende melhor a pronuncia das palavras.

No trecho do memorial da estudante Cássia Eller, identifica-se o ato de cantar contribuindo para a leitura e o canto coral sendo uma atividade que proporciona estímulos e vontade de aprender, que vão além dessa esfera social, visto que a leitura, por exemplo, é constitutiva de práticas realizadas também fora da escola: lê-se em casa, na igreja, na rua e nos diversos contextos que permeiam a sociedade. O canto coral tem, nesse sentido, reflexos que perpassam as práticas 
escolares, mas também de outras atuações sociais. Está sinalizada, nos excertos acima, a questão do desempenho escolar como uma das contribuições do canto no cotidiano dos estudantes: foi a partir das práticas do coral, que eles passaram a perceber melhorias nas suas atuações escolares.

Quando os estudantes relatam que na prática de canto coral eles têm mais vontade de aprender, percebe-se uma relação entre o saber e o sabor reconhecido por Granja, (2010, p.107108).

O saber musical é por natureza saboroso. Quem não se delicia ao ouvir sua música predileta? A música põe em ordem nosso corpo e nossa alma [...] Harmonizar os saberes na escola implica, entre outras coisas, promover essa articulação entre o saber e o sabor, o perceptivo e o cognitivo, a teoria e a prática.

Compreende-se que a música, no contexto educacional, pode favorecer e proporcionar estímulos significativos, podendo contribuir para a aprendizagem dos alunos, o que caminha para a formação integral humana. Colabora no sentido da motivação, da dinamização do processo de construção de conhecimentos escolares. Como Sekeff (2007, p. 81 grifos do original) salienta:

A música é dotada de um poder cujas repercussões imputam sua necessidade na educação. E no caso das escolas ela é também necessária, haja vista esse poder sustentar uma desejada interdisciplinaridade. Como exemplo, na abordagem de temas biológicos é possível a linguagem musical um papel pedagógico ativo, na medida em que, envolvendo órgãos sensoriais receptores de sua fala, particularmente o ouvido (escuta) e a visão (leitura).

O estudante Marcelo D2 escreve em seu memorial que a prática de canto coral fez melhorar o seu desempenho escolar e seus estudos de maneira geral, afirma que pode melhorar ainda mais, o que representa uma compreensão do processo de formação pelo qual está passando. Sinaliza, dessa forma, uma formação interdisciplinar, no sentido de que abrange diferentes áreas do saber por meio da música. Difere, nesse sentido, das estudantes Mallu Magalhães e Roberta Sá quando relatam as disciplinas específicas em que melhoraram com a participação no coro da escola. A estudante (Mallu Magalhães) afirma, ainda, o gosto pela prática musical quando diz "simplesmente amo vir para o coral".

É possível notar o valor que os estudantes atribuem à música, não somente como um conjunto de sons, utilizada apenas para prazer estético. Identificam-se as diferentes funções que eles atribuem à música com em seu cotidiano.

Ainda acerca dos relatos dos estudantes em relação à contribuição da música, observam-se aspectos em comum nos dizeres dos estudantes, como: desempenho escolar, a vontade do aprender. 
A estudante Roberta Sá, porém, traz aspectos que diferem dos outros estudantes, explicitando palavras novas como: expressão, amizade e dedicação.

Roberta Sá (13 anos) - E teve amizades também que levamos para fora do coral, e com isso se ajudavam na escola, no que tínhamos dificuldade, e isso ajudou muito nas notas na escola. E como gostei muito do coral resolvi continuar no coral, e foi no ano que o professor ((nome)) entrou é que nós começamos a trabalhar novos estilos, novas práticas, e começou entrou novas pessoas e com isso criamos novas amizades também. [...] Na hora de apresentar trabalhos na escola eu tenho mais facilidade em falar, não fico travada, e isso tá me dando bem mais facilidade. E o coral também exige muita dedicação, pois são poucas pessoas que deixariam um dia da semana, 4 horas. E eu não faço isso por obrigação, eu faço isso porque eu realmente gosto. $\mathrm{O}$ coral foi uma boa opção para fazer...

Elis Regina ( 7 anos) - Eu cantava muito em casa e a minha e a minha irmã me fez entrar no coral e ainda tenho um pouco de vergonha.

Quando a estudante Roberta Sá expressa que o coral contribuiu para criar novas amizades, que são levadas até mesmo para fora do espaço escolar, nota-se a forte influência que a música tem para a criação de novas relações interpessoais e para deixar o espaço escolar mais harmonioso e humano. Compreende-se que a escola, além de exercer seu papel em desenvolver aprendizagens a partir dos conhecimentos escolares, pode ser responsável por estimular a criatividade dos estudantes, criando ambientes motivadores e desafiadores que favoreçam o pleno desenvolvimento dos educandos. Arroyo (2000) defende que a escola não deve ser uma experiência amarga, excludente, pois nos tornamos mais humanos no grau em que as condições materiais em que vivemos e nas relações que temos com os outros. Para isso, o ambiente precisa ser favorável, pois somente em um clima mais humano nos tornamos humanos.

Outro fator que emerge dos dizeres citados pela estudante é a capacidade de expressão em público. Quando a estudante Roberta Sá afirma que "agora eu tenho mais facilidade em falar", e a estudante Elis Regina diz "ainda" ter um pouco de vergonha, o uso das palavras "agora" e "ainda" está sinalizando que anteriormente, a questão era diferente, isto é, com a participação contínua nas práticas do coral, as educandas estão perdendo a vergonha de se expressar em público. Vergonha, essa, que antes da sua participação, era maior.

Entende-se que aprender música significa ampliar a capacidade perceptiva, expressiva e reflexiva. Joly (2003, p. 113) destaca que a música é uma valiosa ferramenta para o desenvolvimento de inúmeras capacidades humanas, como autoconhecimento e auto expressão. A 
música no cotidiano escolar pode se tornar uma ferramenta para melhor compreender o mundo, não apenas com o objetivo de transmitir um conteúdo, mas sim, o poder de gerar uma transformação no modo de agir do sujeito e contribuindo para suas relações sociais. Dessa forma, a formação escolar vai refletir em outras atuações e esferas sociais, proporcionando uma formação mais ampla de plural dos educandos.

A estudante Roberta Sá descreve em seu memorial, ainda, a troca de professor e a sua permanência no coro da escola. Segundo a estudante, essa mudança implicou novas práticas, outros estilos, e com a saída de alguns alunos e entrada de novos integrantes no coro, possibilitou também diferentes amizades, diálogos e novas relações que aconteceram no coro. A estudante atribui um valor significativo à figura do professor e as mudanças no espaço educativo.

Reflete-se, assim, sobre o real ofício do professor, que segundo Arroyo (2000, p. 54),

O ofício de mestre, de pedagogo vai encontrando seu lugar social na construção de que somente aprendemos a ser humanos em uma trama complexa de relacionamentos com outros seres humanos. Esse aprendizado só acontece em uma matriz social, cultural, no convívio com determinações simbólicas, rituais, celebrações, gestos. No aprendizado da cultura.

Reconhece-se que a escola, enquanto instituição educativa e espaço de formação, faz parte da sociedade, pois promove a cidadania. Entende-se, assim, que um olhar crítico e reflexivo para o contexto escolar é essencial. O professor exerce, portanto, uma função importante no processo de formação dos educandos, função essa que ultrapassa o ensino. Como salienta Freire (2007, p. 41),

A natureza formadora da docência, que não poderia reduzir-se a puro processo técnico e mecânico de transferir conhecimentos, enfatiza a exigência ético-democrática do respeito ao pensamento, aos gostos, aos receios, aos desejos, à curiosidade dos educandos.

Assim, educação não é um dispositivo de ensino de conteúdos, mas é um processo educativo que pode contribuir significativamente para a formação dos educandos, além dos conhecimentos preestabelecidos no currículo escolar. Isso se dá nas relações, em práticas em conjunto, na sensibilidade e na articulação dos saberes com as práticas no cotidiano escolar. Essa interação e convivência refletem, por vezes, na constituição da identidade do sujeito estudante e nas suas relações que vão além da escola. A formação por meio da música e as relações que, de fato, dela emergem colaboram, nesse sentido, para a formação integral dos sujeitos.

Compreende-se que um dos objetivos da música no contexto escolar é contribuir para a formação integral do indivíduo, conforme já vem sido salientado ao longo deste trabalho. Essa 
prática pode refletir, ainda, no desenvolvimento físico, psíquico e cognitivo dos alunos. Para Sekeff (2007, p. 18 grifos do original), a música como agente facilitador, refere-se ao

alcance dessa linguagem nas possibilidades de seus usos e recursos, e seu efetivo concurso no processo de desenvolvimento, individuação, socialização, cognição, criatividade e consciência de cidadania do educando. Tendo em conta que a música, modo peculiar de se organizar experiências, atende a diferentes aspectos do desenvolvimento humano (físico, mental, social, emocional, espiritual), infere-se ser possível recortar seu papel como agente facilitador e integrador do processo educacional, enfatizando desse modo sua importância nas escolas em virtude de sua ação multiplicadora de crescimento.

Compreende-se, então, o espaço escolar como um processo programado de ensino e aprendizagem, mas não visando e pensando a escola somente como: professor, sala de aula e os conteúdos a serem ensinados, mas um espaço de trocas e de convívio com outras pessoas. Espaço no qual as aprendizagens acontecem na sala, nos espaços de convívio em comum, a partir da interação entre sujeitos que têm história, experiências e identidades diferentes.

Dessa forma, a escola é compreendida como um espaço vivo, dialógico e que oportuniza a formação integral em distintas situações. Segundo Arroyo (2000, p. 54), a escola é

é um tempo-espaço programado do encontro de gerações. De um lado, adultos que vêm se fazendo humanos, aprendendo essa difícil arte, de outro lado, as jovens gerações que querem aprender a ser, a imitar os semelhantes. Receber seus aprendizados. Os aprendizados e as ferramentas da cultura.

Nesse espaço no qual são empreendidas distintas e múltiplas relações interpessoais, então, os dizeres dos estudantes levam a pensar no papel da afetividade no processo de ensino e aprendizagem: afetividade que emerge (ou não) das relações estabelecidas na esfera escolar. Pondera-se que, muitas vezes, o ensino é pensado apenas em sua dimensão cognitiva, a dimensão afetiva acaba ficando em segundo plano ou então é desconsiderada, como se as dimensões cognitivas e afetivas estivessem descoladas entre si. Compreende-se que a relação afetiva é crucial para um bom relacionamento entre professor, aluno e demais agentes da escola. Novamente a formação integral está imbricada nesse processo, pois a formação plena visa a todas as dimensões que fazem parte de um sujeito, um sujeito múltiplo, integral e dialógico que se relaciona com outros sujeitos múltiplos, integrais e dialógicos.

Para além das contribuições no campo escolar de atuação do estudante, o coral também apresenta reflexos na atuação além de escolar, os diários reflexivos dos estudantes atribuem um 
valor à música para as práticas sociais que estão além dos muros da escola. Neste momento, então, são discutidos dizeres atrelados ao comprometimento, relacionamento e outras dimensões afetivas. Constantemente, os alunos relacionam a música com alguma outra questão, ou seja, a música por si só, muitas vezes, é esquecida, mas funções sociais são sempre lembradas.

Compreende-se que um dos fatores que contribuem para esse reconhecimento mais social das funções da música é que ela está presente em diversos lugares, expressa-se em diferentes formas e ritmos, em contextos culturais diferenciados de celebrações ou comemorações, em espaços diversos como instituições religiosas, festas, bem como em trilha sonora de filmes e outras atividades que os sujeitos empreendem em seu cotidiano. Como afirma Penna (2008), a música está em toda parte, seja ela para exaltar momentos de alegria ou tristeza, pois, “[...] a nossa experiência com música acontece através da interação com 'músicas' diferenciadas, ou seja, com diversificadas manifestações musicais concretas, de enorme multiplicidade" (PENNA, 2008, p. 48).

Pauta-se, então, nas contribuições de autores como Penna (2008) e Swanwick (2003) para discutir a música e suas funções sociais. Para esses autores, a música é uma linguagem da arte que está presente desde as tribos indígenas até as grandes cidades. Desse modo, ela está enraizada em diferentes povos e culturas, ainda que de diferentes formas. Compreende-se que a música não só está inserida no contexto social, mas nasce a partir de diferentes contextos sociais. Ao ouvir uma música, é possível sentir várias sensações, podemos, então, dizer que ela está ligada também às emoções. Para Swanwick (2003), a música pode ser agradável, manter as pessoas afastadas das ruas, gerar empregos, engrandecer eventos sociais. Dessa forma, nota-se a sua significativa influência na sociedade.

À luz dessas concepções, passa-se às funções que os estudantes, participantes desta pesquisa, atribuem à música. Nesse sentido, nota-se a relevância da música como função social. Neste momento, apresentam-se dizeres dos estudantes analisados. A seguir, apresentam-se excertos que dizem respeito à vivência e convivência social dos estudantes em outros âmbitos que não a escola, dizem respeito mais especificamente às relações sociais e afetivas que os estudantes relacionam à música:

Chorão (11 anos) - melhorei na escola, em casa, e em muitos lugares e, muitas músicas que são muito legais que aprendi e que agora gosto muito, conheci muitas pessoas legais, como os professores, alunos do coral. Com a música eu consigo relaxar conversar com as pessoas, etc. 
Maria Gadú (12 anos) - E na minha casa também eu estou melhorando a paciência que eu tenho com meu irmão é bem mais sei la tipo melhorou porque eu brigava muito com ele, ele é mais novo e consegue tudo o que quer.

Nos dizeres dos estudantes Chorão e Maria Gadú, é possível identificar um aspecto relevante relacionado ao relacionamento e ao convívio social com pares sociais, além dos professores e colegas de escola. No caso da estudante Maria Gadú, a música contribui especificamente para o relacionamento familiar, exemplificado pela relação com o seu irmão. $\mathrm{O}$ excerto da estudante remete a Bastian (2011, p. 39) quando, em sua pesquisa, comenta que "a familiaridade com a música 'abre' as pessoas aos seus semelhantes. [...] visto que a música, como meio de contato, pode ter efeitos socializadores e éticos-sociais". Compreende-se que o aumento da paciência com o irmão, conforme relata a estudante, tem influência do que Sekeff (2007) chama de emoção musical: por meio de elementos musicais como ritmo, melodia, intensidade, harmonia, duração entre outros, a música favorece distintas induções que estão atreladas às emoções. Para Sekeff (2007, p. 61, grifos do original),

A emoção musical, como a emoção em geral, principia por uma excitação nervosa, manifestando um esquema de reações que ocorrem nos tecidos nervosos e que são a fonte física da emoção. Como nossos nervos podem se excitar pela ação de fenômenos físicos e psíquicos, a emoção musical promove respostas tanto fisiológicas quanto psicológicas. O som, fenômeno físico/acústico, matéria da música, afeta o sistema nervoso autônomo, base da reação emocional, e as respostas fisiológicas que suscita são diretamente ligadas às vibrações sonoras.

As emoções estão, assim, intimamente ligadas à interação na prática do canto coral e nas relações interpessoais que delas emergem. A música figura como elemento de união entre as pessoas e intermediária de relações de socialização não apenas com os pares imediatos no âmbito do coral dos sujeitos desta pesquisa, mas reflete também nas relações em casa, como sinaliza a estudante Zélia Duncan:

Zélia Duncan (13 anos) - A música contribui na escola e na minha vida pessoal com minha família na escola até melhorei nas notas para continuar no coral, e na família tenho muito apoio no que gosto de fazer, que é com certeza cantar, mas já tive consequências de sair do coral, mas com isso aprendi que no coral e nas consequências e obstáculos para enfrentar ou ultrapassar e com isso e mais um pouco eu gosto muito do coral.

Os dizeres da estudante Zélia Duncam apontam para as suas relações afetivas. Segundo a estudante, por meio da prática de canto coral, a música contribuiu para a sua vida pessoal e sua 
relação com a sua família. A estudante Zélia Duncam menciona que conta com o apoio dos familiares nas atividades que deseja fazer e demonstra seu interesse na participação do coro, que relaciona com a coragem e enfrentamento dos obstáculos e desafios que passa no cotidiano. Dessa forma, a música ganha uma nova função: a motivação para novas descobertas e vivência de experiências que, talvez, não fosse o impulso construído nas relações afetivas com sua família e mediado pela música, não aconteceriam.

Nesse sentido, reflete-se sobre a forma como os sujeitos se constituem e desenvolvem, inseridos em situações mediadas pela música. O desenvolvimento dos sujeitos está sempre inserido em um contexto singular e específico que pode refletir em aspectos desse desenvolvimento. Apresenta-se, então, neste momento, o dizer da estudante Janis Joplin:

Janis Joplin (14 anos) - aqui é diferente a gente canta, ri, se diverte, faz brincadeiras e claro a gente faz um lanchinho. Já ouvi meus professores falarem que o coral me faz ficar mais atenta nas aulas, meus pais falaram que fiquei mais responsável, menos chata, eu simplesmente mudei bastante depois que entrei no coral, eu mesma consigo perceber que mudei, deixei de ser aquela garotinha que não levava as coisas muito a sério, [...] Não gosto nada da ideia de que ano que vem vou ter que sair do coral, pois é, não sei se porque esse é o meu último ano mas está passando tão rápido. Não consigo imaginar como vai ser ficar sem o coral, vai ser muito ruim quando chegar a terça-feira e ao invés de vir para o coral ter que ir trabalhar, mas vou aproveitar o tempo que resta.

Esse dizer chama a atenção quando a estudante afirma que "aqui é diferente". Entende-se que a estudante faz uma analogia com outros espaços sociais, especialmente na escola, pode-se dizer que ela entende o coral como um espaço para além de escolar? Compreende-se que a estudante pode estar pensando assim, pelo fato de que a prática musical de canto coral acontece no período extracurricular, sem as disciplinas fragmentadas e sem as formalidades diárias da escola.

Conforme Costa (2013, p. 33), o canto coral vem ao encontro das necessidades de identificação dos jovens como um meio de expressão que lhe possibilite explicitar ao mundo os seus anseios, descobertas, ideias e revoltas. Por meio do canto, o adolescente pode experimentar diferentes aspectos de suas transições, sejam elas fisiológicas ou psicossociais.

A estudante Janis Joplin, em seu memorial, traz aspectos já mencionados por outros estudantes como o desempenho escolar e relações interpessoais (dimensões discutidas na categoria anterior de análise deste trabalho), mas o que chama a atenção no dizer da aluna é que "deixei de ser aquela garotinha que não levava as coisas muito a sério". Atribui-se essa fala à construção de 
identidade, personalidade da estudante. Ao participar de práticas do coral, a estudante sinaliza que se sente parte desse contexto, a inserção em atividades de uma determinada esfera reflete na forma como o sujeito compreende e projeta a imagem de si mesmo. Nesse sentido, o processo de formação pelo qual passou durante a sua participação no coral contribuiu para a sua constituição identitária e, para, além disso, refletiu na forma como ela interage nas práticas sociais, visto que, segundo a aluna, ela passou a levar as coisas mais a sério.

Ao ponderar sobre sua saída da atividade musical, a estudante menciona que "Não consigo imaginar como vai ser ficar sem o coral”. Esse dizer sinaliza, mais uma vez, a relação entre a prática do canto e sua constituição identitária: ocorre uma desestabilização na forma como a estudante compreende a si e seu papel social a partir do momento que considera ter que deixar de participar das atividades empreendidas no âmbito do coral.

Ainda sobre as funções da música enquanto elo afetivo entre os estudantes que participam do coral e os demais membros da sociedade, Adriana Calcanhoto salienta que:

Adriana Calcanhoto (13 anos) - Eu acho que o coral está melhorando e contribuindo mais na minha vida pessoal, porque agora estou aprendendo a ter técnicas vocais e também estou mais contente por que passo o meu tempo fazendo uma coisa que sempre foi especial pra mim, o coral também melhorou o relacionamento comigo com os meus pais agora eles também veem minhas apresentações que sempre os deixam muito orgulhosos e felizes.

A estudante menciona os conhecimentos específicos de música, salientando que está aprendendo técnicas vocais. Além das contribuições e funções da música refletindo na esfera social dos estudantes, é possível identificar, aqui, a música como área de conhecimento específico e isso justifica o fato de que ela precisa ser contemplada nas instituições escolares, pois faz com que a estudante se sinta contente por estar praticando algo que é especial para ele. Identifica-se uma relação de afetividade para com o coral. E, quando a estudante relata que "o coral também melhorou o relacionamento comigo com meus pais", sinaliza que os pais se sentem felizes e orgulhosas quando assiste a estudante nas apresentações. Novamente a dimensão afetiva está presente, mais uma vez, o sentimento e a emoção estão imbricados na fala da estudante. Essa questão remete a Mahoney e Almeida (2007, p. 18) quando defendem que a emoção

É a exteriorização da afetividade, é sua expressão corporal, motora. Tem um poder plástico, expressivo e contagioso; é o recurso de ligação entre o orgânico e o social: estabelece os primeiros laços com o mundo humano e, através deste, com o mundo 
físico e cultural. [...] A emoção é uma forma de participação Mútua, que funde as relações interindividuais.

Compreende-se, nesse sentido, que a música foi um elo afetivo entre a estudante e sua família, meio pelo qual ela pode se projetar como um sujeito singular e, nesse processo, aprofundar suas relações sociais com os familiares. A música e afetividade estão, neste caso, intimamente ligadas e são exteriorizadas quando a estudante se apresenta e tem, em seu público, a própria família.

A participação na prática musical pode possibilitar o desenvolvimento dos indivíduos, sujeitos que fazem parte da sociedade, exercendo a sua cidadania. Sendo assim, identifica-se a responsabilidade de extrema importância, conforme citado pela aluna. Distintas contribuições emergiram dos dizeres dos estudantes em relação à prática musical que participam na escola. Contribuições nas relações sociais e afetivas com amigos e família, que transcendem o espaço escolar e ganham as ruas.

\section{CONSIDERAÇÕES FINAIS}

Conforme sinalizado na seção de introdução, este artigo foi guiado pelo objetivo de analisar as possíveis contribuições do canto coral para a formação integral de estudantes. Para tanto, foram analisados dizeres de estudantes participantes de práticas de canto coral em uma escola pública de Santa Catarina.

No que diz respeito ao desenvolvimento escolar, os participantes mencionaram aspectos relacionados com a aprendizagem da leitura, da escrita; que a prática do canto facilitou a pronúncia de várias palavras e na expressão para apresentar trabalhos escolares. Foram citadas, também, contribuições para algumas disciplinas como português, matemática, inglês e história.

Já em relação ao desenvolvimento intelectual, identificou-se nos dizeres dos estudantes, a dedicação, a atenção e a vontade de aprender. Por meio desses fatores, entende-se que o canto coral reflete tanto no desenvolvimento intelectual como na construção de novos saberes.

O convívio social também foi sinalizado, no que diz respeito às amizades, à superação da vergonha, à facilidade que a música promoveu em falar em público, ao aprimoramento na expressão, à socialização e houve, inclusive, a menção ao fato de que o coral da escola se tornou uma segunda família. Vale ressaltar, neste momento, a interferência da prática de canto coral no estudante com o meio social. 
Além das contribuições que transcendem os muros da escola, os estudantes também citaram os conhecimentos musicais específicos construídos na prática de canto coral como afinação, senso rítmico, timbre e técnicas ligadas ao canto. Outro aspecto relevante é a construção de perspectiva acadêmica e a música auxiliando os alunos nas diferentes atividades cotidianas. A persistência e o conhecimento construído por meio da prática musical também foram destacados.

Se o objetivo da formação integral é ultrapassar os muros da escola e considerar a formação plural do sujeito em sua múltipla dimensionalidade, é possível identificar que a aprendizagem musical reflete diretamente nessa dimensionalidade e na vida social dos estudantes. O olhar dos alunos sobre a prática do canto na escola trouxe subsídios significativos assinalando como a música pode auxiliar no desenvolvimento cognitivo, afetivo e nas relações interpessoais dos estudantes. 


\section{REFERÊNCIAS}

ANDRÉ, Marli. Memorial, instrumento de investigação sobre o processo de constituição da identidade docente. Contrapontos, v. 4, n. 2, 2004. Disponível em: < http://siaiap32.univali.br/seer/index.php/rc/article/view/782>. Acesso em: 18 mar. 2016.

ARROYO, Miguel Gonzales. Ofício de Mestre: imagens e auto-imagens. Petrópolis, RJ: Vozes, 2000.

BASTIAN, Hans Günther. Música na escola: a contribuição do ensino da música no aprendizado e no convívio social da criança. 3. ed. São Paulo: Paulinas, 2011.

BRASIL. Lei 9.394, de 20 de dezembro de 1996. Estabelece as diretrizes e bases da educação nacional. Diário Oficial da União. Brasília: Poder Legislativo, 23 dez. 1996, sec. I, n. 248, p. 27.833. . Disponível em: <http://portal.mec. gov.br/arquivos/pdf/ldb.pdf>. Acesso em: 18 ago. 2014.

BRASIL. Manual operacional de educação integral. Ministério da Educação. Brasília, 2014.

COSTA, Patricia. O uso da voz no coro juvenil. In: SOBREIRO, S. Desafinando a Escola. Editora Musimed, 2013.

EL-GUINDY, Moustafa. Metodologia e ética na pesquisa científica. São Paulo: Santos, 2004.

FREIRE, Paulo. Política e Educação. 8. ed. Indaiatuba, SP: Villa das Letras, 2007.

GRANJA, Carlos E.S. Campos. Musicalizando a escola: música, conhecimento e educação. 2. ed. São Paulo: Escrituras Editora, 2010.

GUARÁ, Isa M.F. Rosa. É imprescindível educar integralmente. Cadernos Cenpec: Educação Integral. São Paulo: Cenpec, n. 2, 2006.

HENTSCHKE, Liane; DEL BEN, Luciane. Aula de música: do planejamento e avaliação à prática educativa. In: HENTSCHKE, L; DEL BEN, L. (Orgs.). Ensino de música: propostas para pensar e agir em sala de aula. São Paulo: Ed. Moderna, 2003. p. 176-189.

JOLY, Ilza Z. Leme. Educação e Educação Musical: conhecimentos para compreender a criança e suas relações com a música. In: HENTSCHKE, L.; DEL BEN, L. (Org.). Ensino de música: propostas para pensar e agir em sala de aula. São Paulo: Moderna, 2003. p. 113-125.

MAHONEY, Abigail A.; ALMEIDA, Laurinda R. Afetividade e Aprendizagem: contribuições de Henri Wallon. São Paulo: Loyola, 2007.

PENNA, Maura. Música(s) e seu Ensino. Porto Alegre: Sulina, 2008.

RAITZ, Tania R.; FERREIRA, Valeria S.; GUERRA, Antonio F. (Orgs.). Ética e Metodologia: pesquisa na educação. Itajaí, SC: Fundação Universidade do Vale do Itajaí, 2006.

SEKEFF, Maria de Lourdes. Da música, seus usos e recursos. 2. ed. São Paulo: Editora UNESP, 2007.

SWANWICK, Keith. Ensinando Música Musicalmente. São Paulo: Moderna, 2003. 


\section{RESUMO}

No contexto escolar a formação integral abrange diferentes dimensões do sujeito, forma-se para além de práticas escolarizadas; inclui-se convívio e interação social com outros sujeitos e discursos. Práticas musicais podem fazer parte dessa formação, pois a música está presente em diversas esferas sociais. Este artigo, então, objetiva analisar as possíveis contribuições do canto coral para a formação integral de estudantes. Para tanto, analisam-se memoriais descritivos de alunos de escola pública participantes de encontros semanais do canto coral. Compreende-se que as práticas empreendidas refletem na transformação de aspectos escolares, como atenção e aprendizagens em diferentes disciplinas; e em práticas (além de) escolares, como relação com a família e projeção que o estudante tem de si.

Palavras-chave: Canto coral. Formação integral. Coral na escola.

\section{CHORAL SINGING CONTRIBUTIONS AT SCHOOL FOR INTEGRAL EDUCATION: WHAT STUDENTS SAY}

\section{ABSTRACT}

In the school context, the integral education encompasses different dimensions of the subject, it is formed in addition to school practices; it includes social interaction and interaction with other subjects and discourses. Musical practices can be part of this education, since music is present in several social spheres. This article, then, aims to analyze the possible contributions of choral singing to the integral education of students. For that, descriptive memorials of public school students participating in weekly choral singing meetings are analyzed. It is understood that the practices undertaken reflect in the transformation of school aspects, such as attention and learning in different disciplines; and in (besides) school practices, as a relation with the family and the projection that the students have of themself.

Keywords: Choral singing. Integral formation. Coral at school.

\section{CONTRIBUCIONES DEL CANTO CORAL EN LA ESCUELA PARA LA FORMACIÓN INTEGRAL: QUÉ DICEN LOS ESTUDIANTES}

\section{RESUMEN}

En el contexto escolar, la formación integral abarca diferentes dimensiones del sujeto, se forma más allá de prácticas escolares; se incluye la convivencia e interacción social con otros sujetos y discursos. Las prácticas musicales pueden formar parte de esta formación, pues la música está presente en diversas esferas sociales. Este artículo, entonces, tiene como objetivo analizar las posibles contribuciones del canto coral para la formación integral de estudiantes. Para ello, se analizan memorias descriptivas de alumnos de escuela pública participantes de encuentros semanales del canto coral. Se entiende que las prácticas emprendidas reflejan en la transformación de aspectos escolares, como atención y aprendizajes en diferentes disciplinas; y en prácticas (además de) escolares, como relación con la familia y proyección que el estudiante tiene de sí.

Palabras clave: Canto coral. Formación integral. Coral en la escuela. 